\title{
ILCEA
}

Revue de l'Institut des langues et cultures

d'Europe, Amérique, Afrique, Asie et Australie

$24 \mid 2015$

Lire et écrire ensemble

\section{Todas las primeras veces, o sea siempre}

\section{César Aira}

\section{OpenEdition \\ Journals}

\section{Edición electrónica}

URL: http://journals.openedition.org/ilcea/3673

DOI: 10.4000/ilcea.3673

ISSN: 2101-0609

Editor

UGA Éditions/Université Grenoble Alpes

\section{Edición impresa}

ISBN: 978-2-84310-313-1

ISSN: $1639-6073$

Referencia electrónica

César Aira, «Todas las primeras veces, o sea siempre », ILCEA [En línea], 24 | 2015, Publicado el 02 noviembre 2015, consultado el 24 septiembre 2020. URL : http://journals.openedition.org/ilcea/3673 ; DOl : https://doi.org/10.4000/ilcea.3673

Este documento fue generado automáticamente el 24 septiembre 2020

(C) ILCEA 


\title{
Todas las primeras veces, o sea siempre
}

\author{
César Aira
}

1 Conocí a Michel hace años, ahora me parecen muchísimos años, en un coloquio en Aix. Yo era el único escritor argentino invitado, y lo habían llamado a él para presentarme, en tanto "argentinista", término del que, si no fue el inventor, terminó siendo el más ilustre representante. No había leído entonces ningún libro mío, pero aceptó la propuesta y leyó los que consiguió en el momento. Hubo un diálogo en público, su presentación y sus preguntas fueron tan atinadas e inteligentes que me hizo sentir inteligente a mí, efecto que se repetiría en el futuro. Muchos años después (y creo que fue la última vez que nos vimos) yo presenté un libro suyo, y le hice preguntas ante el público, y otra vez me hizo sentir inteligente.

2 Aquella vez en Aix, la mañana antes del evento, se había presentado. Fuimos a un café que yo, snob impenitente, quería conocer porque sabía que lo había frecuentado Diderot. Michel, sentado frente a mí, desplegó metódicamente sus antecedentes académicos: un artículo en una revista donde exponía sus proyectos y método de trabajo, otro artículo que podía servir de ejemplo de lo anterior, y su gran libro sobre Borges. Tanta formalidad no estaba fuera de lugar en él, se naturalizaba en el perfecto orden mental y la consiguiente claridad sin repliegues que no desmintió nunca.

El recuerdo privilegia las primeras veces, las atesora y pone en perspectiva, a la luz de lo que hubo después. La primera vez que nos vimos en Buenos Aires, en su primer viaje, el primer día. Nos encontramos en un café. Salimos a caminar, le pregunté qué quería ver, lo dejó a mi elección, era su primera salida. Propuse ir a la casa de Borges, lo que no podía ser más previsible y obvio.

4 La primera vez que leí Tintin. Fue en aquel primer viaje suyo. Con mudo escándalo descubrió que yo lo ignoraba todo de la obra de Hergé. Eso había que remediarlo sin demora. Al día siguiente me regaló tres álbumes, cuidadosamente elegidos como introducción, dejando las obras maestras para más adelante (pero uno era L'affaire Tournesol, uno de sus favoritos). Esa noche yo los había leído, y hablamos por teléfono. "Tintin es el vacío que hace girar a su alrededor la aventura", aventuré al oído del gran 
conocedor. Estuvo de acuerdo. Me dijo que había una expresión coloquial infantil, que yo no conocía, que confirmaba mi intuición: "Faire tintin significa no hacer nada". Con los años Tintin se volvió uno de los temas en los que nos sentíamos cómodos y siempre había algo nuevo que decir. No había muchos temás más. No los necesitábamos para que el diálogo tuviera toda la variedad que nos alimentaba. Una vez, ya viejos los dos, Borges le dijo a Bioy (en cuyo diario está la frase): “ ¿Te das cuenta de que hace cuarenta años que mantenemos la misma conversación?" No hay mejor definición de una amistad prolongada. Y la amistad de verdad dura toda la vida. (Es la vida la que, tristemente, no dura toda la vida.)

5 La primera vez que estuve en su casa de Voreppe, la primera de una serie que me dio el descubrimiento y el placer de lo maravilloso cotidiano. Michel me fue a buscar al aeropuerto de Lyon, en el auto reanudamos la conversación suspendida en Buenos Aires. Tanto debíamos tener que decirnos, y tanto nos absorbía, que se perdió y terminamos en la frontera de Suiza. Al llegar a la casa, Ana nos esperaba en la puerta: Michel se completaba. La casa era su retrato en tres dimensiones, o en cuatro porque había también una perspectiva temporal. Descifrarla, entrar en el jardín de senderos que se bifurcan de los intereses y saberes de su dueño, en su luminosa erudición lúdica, fue uno de mis grandes placeres intelectuales.

6 La primera vez que viajamos juntos, a Santander, la ciudad más fea de España. Pero nos alojaron en un palacio frente al mar, y conocimos a un joven escritor gallego que se volvió un amigo entrañable de los dos. No fue el único que nos acompañó en la amistad. Los amigos comunes, al revés de lo que pasa con los terceros en una pareja, unen más a los dos amigos, estrechan el lazo.

7 En nuestros paseos por Santander comprobábamos en cada calle lo fea y triste que era. Pero la ciudad había sido destruida por un incendio, y reconstruida. Fantaseábamos que la ciudad desaparecida había sido la más bella del mundo, y eso solo transfiguraba la que recorríamos. Al pasar por un lúgubre edificio gris, Michel me señaló una placa, con unas palabras en latín: Prima ex igni renata. La primera casa que renació de las llamas, el punto de partida de la reconstrucción. Quizás había sido antes un palacio de mármol blanco. Miramos con más respeto el edificio, y la calle, y la ciudad. Michel había sido experto latinista en su juventud, y había renacido como hispanista, preservando los palacios de mármol de la prosa razonada y la sintaxis elegante.

8 Podría seguir enumerando las primeras veces de nuestra amistad y no terminaría nunca, porque dentro de cada primera vez hay otras primeras veces, innumerables, proliferando en la memoria. La primera vez que fuimos juntos a una librería de viejo, en Grenoble; Michel descubrió una novela de Maurice Renard que nos llevó a otras novelas de Renard, y a meses de felices lecturas. La primera vez que lo acompañé a un supermercado. Llevaba el consabido listín confeccionado por la esposa; obedeciéndolo, fue a las "blattes", y las estaba seleccionando; yo me había alejado, pero lo vi mover los labios; me acerqué, y oí que estaba canturreando un tango. "Arrabal amargo..." Lo inolvidable también es frágil, y necesita el hilo de una melodía para subir hasta la memoria.

Lo argentino de nuestro amigo francés tenía el sustrato universal que le había dado Borges, al que había venido siguiendo la primera vez. Nos volvió a todos sucedáneos de Borges, hasta a los que menos lo merecíamos. Nos hizo su objeto de estudio, pero, como los antropólogos que al instalarse en una tribu selvática para observarla les enseñan a 
los nativos a usar la cámara, el grabador y la aspirina, y terminan modificando la realidad a estudiar, así Michel nos cambió y enriqueció. 